\title{
Controle de qualidade no laboratório de análises clínicas
}

Desde o século passado, percebe-se, em todas as situações, uma importante evolução no conceito de qualidade, particularmente, diante das exigências dos clientes. Em consequência disso, o "melhorar continuamente os processos" passou a ser meta e conduta de toda instituição ou organização. Nos laboratórios clínicos, isso não foi diferente. Em face dessas exigências, a melhoria da qualidade do produto oferecido (resultado de exames) e seu controle foram as consequências naturais desse processo.

O laboratório clínico deve assegurar que os resultados produzidos reflitam, de forma fidedigna e consistente, a situação clínica apresentada pelos pacientes, assegurando que não representem o resultado de alguma interferência no processo. A informação produzida deve satisfazer as necessidades de seus clientes e possibilitar a determinação e a realização correta de diagnóstico, tratamento e prognóstico das doenças.

A melhoria contínua dos processos envolvidos deve representar o foco principal de qualquer laboratório. Para isso, procura-se oferecer, cada vez mais, os melhores produtos ou serviços para os clientes.

Entretanto, para que as inovações e melhorias deem certo, torna-se imprescindível o controle desses processos, que deve ser capaz de identificar possíveis falhas que possam vir a acontecer ou as que já aconteceram. Além disso, o laboratório deverá estar preparado para agir prontamente para evitar ou minimizar as consequências e a recorrência dessas falhas. Isso tudo acaba por se traduzir em um processo chamado garantia da qualidade.

Em um laboratório de análises clínicas, a garantia da qualidade é alcançada tendo-se total e absoluto controle sobre todas as etapas do processo, o qual pode ser denominado de realizar exame, que compreende as fases pré-analítica, analítica e pós-analítica.

A gestão da qualidade, por sua vez, abrange as ações utilizadas para produzir, dirigir e controlar essa qualidade, incluindo a determinação de uma política e de objetivos da qualidade, com o uso de indicadores e metas.

A garantia da qualidade de todas as fases pode ser conseguida por meio da padronização de cada uma das atividades envolvidas, desde o atendimento ao paciente até a liberação do laudo. Com isso, pode-se alcançar a qualidade que se almeja e, com a gestão da qualidade, garanti-la.

Todas essas atividades no laboratório devem ser documentadas por meio de procedimentos operacionais padrão (POP) ou instruções de trabalho (IT), que deverão estar sempre acessíveis aos funcionários envolvidos nas atividades.

Com a incessante procura por qualidade nos processos laboratoriais, foram criados os programas de acreditação brasileiros, como o Programa de Acreditação de Laboratórios Clínicos (PALC) da Sociedade Brasileira de Patologia Clínica/Medicina Laboratorial (SBPC/ML), e o Departamento de Inspeção e Credenciamento da Qualidade (DICQ) da Sociedade Brasileira de Análises Clínicas (SBAC). Além disso, surgiram, no Brasil, nas décadas de 1970-80, os programas de controle da qualidade em laboratório clínico, como o Proficiência em Ensaios Laboratoriais (PELM) e o Programa Nacional de Controle de Qualidade (PNCQ). Esses sistemas são utilizados para atender às necessidades de ampla e melhor avaliação dos laboratórios clínicos.

Com a qualidade melhorada, os desperdícios podem ser evitados, reduzindo-se os custos e aumentandose a produtividade, e, com isso, haverá melhora da competitividade no mercado. 